\title{
Music and the brain, literally
}

\author{
Joseph LeDoux ${ }^{1,2 *}$ \\ 1 Center for Neural Science and Department of Psychology, New York University, New York, NY, USA \\ 2 Emotional Brain Institute, Nathan Kline Institute for Psychiatric Research, Orangeburg, NY, USA \\ ${ }^{*}$ Correspondence: ledoux@cns.nyu.edu
}

I spend my days working on the brain, specifically on how it makes mind and behavior possible. Most everyone believes that mind and behavior depend on the brain. But just how it all works is still mysterious. We have learned a lot, but we have got a long way to go.

My particular area of research is about the relation between emotion and memory. For the past 25 years or so I have been using a simple behavioral paradigm, Pavlovian fear conditioning, to try to understand how the rat brain (and by inference, the human brain) learns and stores memories about threatening situations. In Pavlovian fear conditioining a rat is exposed to a sound that is followed by a mild shock. The sound comes to elicit fear responses, such as freezing behavior, autonomic nervous system responses, and hormonal responses. By tracing the circuits forward from the auditory system to the response control systems, we implicated specific regions of the amygdala in the learning and storage of these memories. This kind of memory is different from what we usually mean by the term memory. It is not memory that you consciously recall and reflect on. It is implicit or unconscious memory. In the early 1990s, I introduced the concept of emotional memory (LeDoux, 1992a,b,c), which built upon the distinction between declarative/explicit memory and non-declarative/procedural/implicit memory (Squire, 1986). Thus, emotional memory (the implicit or unconscious kind of memory created by fear conditioning) was distinguished from cognitive memory about emotion (the kind of conscious memory one might have about a situation in which emotional memories are learned and stored). The former depends on the amygdala and the latter on the hippocampus and other components of the medial temporal lobe memory system (LeDoux, 1996, 2002, 2007a,b).

Work by my lab and others has made a lot of progress in pinpointing the neural system centered on the amygdala that is involved in the learning and storage of emotional fear memory, as well as the synaptic, cellular, and molecular mechanisms involved (for reviews see: LeDoux, 1996, 2000, 2002, 2007a,b; Walker et al., 2003; Maren and Quirk, 2004; Rodrigues et al., 2004; Fanselow and Poulos, 2005; Maren, 2005; Phelps and LeDoux, 2005; Sah et al., 2008; Pape and Pare, 2010; Tully and Bolshakov, 2010).

Research is difficult these days. Neuroscientists not only have to try and crack the hardest code unknown to man, we also have to convince our colleagues sitting on funding panels that our particular idea about how to make a little progress is what they should bless with an influx from the shrinking pot of government research money. So it is good to have a way to relax.

At some point in every day I have a guitar in my hands, unless I am traveling and without my sonic security blanket. Sometimes I just strum some chords. Other times I work on a rhythm pattern, or I attempt to fine-tune some vocals so that they are in harmonic alignment with the chords (or at least close). Other times I am rehearsing or playing with my friends and band mates in The Amygdaloids (www.amygdaloids.com).

In the early fall of 2006 I was invited to give a lecture on my work on emotions and the brain to the Secret Science Club. This was and still is a thriving science-for-thepublic program held in a bar in Brooklyn. It draws on the amazing reservoir of scientific researchers in the New York City area, having a speaker once a month. The organizers said they would find some entertainment to follow my talk. I said I would bring the entertainment.

For a couple of years, Tyler Volk and I had been playing guitar together, alternating between each other's apartment. Tyler is a Professor in Biology, with a specialty in environmental science, but with a serious fascination with mind and brain (I consider him a closet cognitive neuroscientist). At one point Daniela Schiller, a postdoc in cognitive neuroscience at NYU, joined us on drums at a party. When we got the Brooklyn gig, Daniela invited her research assistant, Nina Curley, to play bass. We marched off to the Secret Science Club as The Amygdaloids.

Since we were a neuroscience band, we decided to focus our set on songs about mind and brain and mental disorders. We played some covers (Manic Depression, 19th Nervous Breakdown) and a couple of original tunes I wrote (Mind Body Problem, All in a Nut- the latter being about the amygdala, which is named after the Greek work for almond). A local newspaper described our show with the label, "Heavy Mental."

By the summer of 2007 we had put together enough original tunes to put out a $\mathrm{CD}$, which we of course named "Heavy Mental." Included were songs like A Trace (a love, song about the synaptic basis of memory), Inside of Me (a lyrical portrayal of Descartes' idea that one's mind can only be truly known internally), When the Night Is Dark (about fear), Mind Body Problem (a love song about the struggle between passion and reason), and An Emotional Brain (also about the difficulty of controlling our emotions). The songs were recorded at Axis Studios in Manhattan (Jeff Peretz and Steve Rossiter, producers).

We have played in various juke joints and clubs around NY, and also in some pretty fancy venues - Madison Square Garden (for NYU's graduation) and the Kennedy Center in Washington DC (a real gig). The big venues are fun, but there's something special about dark, dank clubs like Kenny's Castaways, where decades of beer fumes exude from walls that once contained the sounds of Dylan, Springsteen, and other giants in their early days. Some of the other clubs we have played around New York include Arlene's Grocery, Don Hill's, Lakeside Lounge, and Otto's Shrunken Head.

By 2008 we had a whole new set of songs, and had hooked up with an independent record label, Knock Out Noise, which agreed 
to record our second CD. It was originally titled, "Brainstorm," but eventually formally released as "Theory of My Mind (Figure 1)." This title obviously is a play on the notion in psychology and philosophy known at theory of mind, the idea that social interactions between people involve in part the ability to put oneself in the shoes (mind) of another. Theory of My Mind featured Grammy winning artist Rosanne Cash doing back up vocals on two songs, and Simon BaronCohen, leading proponent of idea that theory of mind is impaired in autism, on bass. "Theory of My Mind" had a lot of music on it, 13 songs in all. We explored questions about memory (Mist of a Memory; Glue), free will (How Free Is Your Will; Crime of Passion; the Automatic Mind), the relation of mind and matter (Mind Over Matter; Piece of My Mind), emotions (Fearing), mental time travel (Imaginate), neurophysiology (Refractory Time), mental illness (Brainstorm), and, of course, theory of mind (Theory of My Mind).

In addition to getting to record with Rosanne Cash, we have gotten to play with or be on the same bill with, some amazing musicians, including Lenny Kaye (Patti Smith Group), Steve Wynn (Dream Syndicate, The Baseball Project), Gary Lucas (Capitan Beefhart; Gods and Monsters), Dee Snider (Twisted Sister), The Kennedys, and Rufus Wainwright.

Tyler, Daniela, and I have been the core of the band from the start. Bass has been a moving target. When Nina left NY to pursue other interests, I brought in Gerald McCollam, an old friend who had run the teaching lab in the Center for Neural Science several years earlier. But then his freelance programming work took him back to Louisiana, where we both grew up. Recently, Amanda Thorpe took over bass. Amanda has an angelic voice, and an independent career in the New York music scene. She fits the band well having studied neuropsychology at University College London.

I get asked quite a lot about the relation of music and the brain. But that's not really my area of research. I try to connect music and the brain lyrically rather than through scientific activity. I do not have any formal musical training, and do not really know what the right questions to ask are. I suppose I could come up with some studies of emotion and music, but have not felt that urge. Some

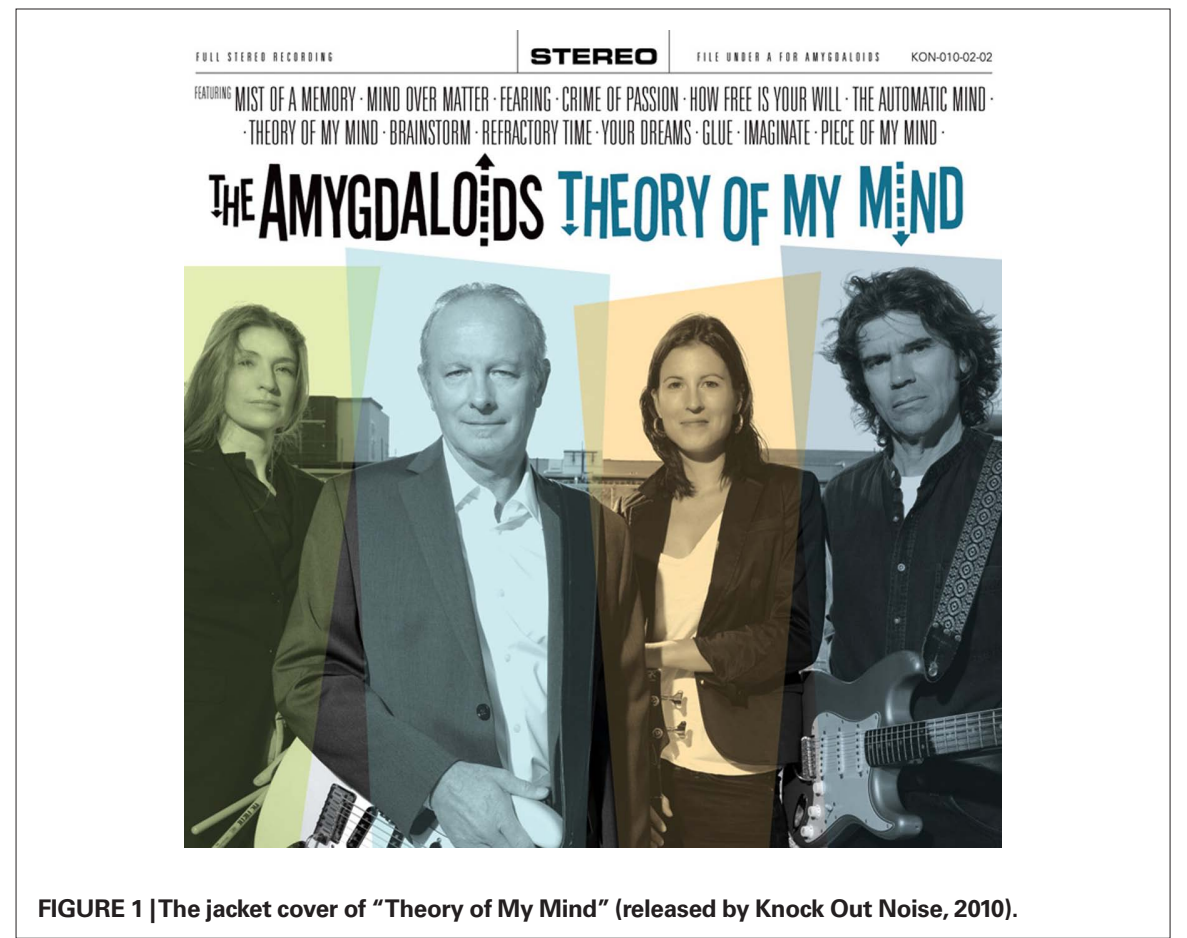

really talented scientists are involved in this field, such as Robert Zatorre, Dan Levitin, Mark Tramo. They are doing a fabulous job of uncovering all sorts of fascinating things about how the psychology of music relates to the biology of the brain. I am just happy to writes songs and play music.

Music is not just fun. It is also a great communication device. I have used books to communicate science to the-public in the past. My two main books, The Emotional Brain (1996) and Synatpic Self (2002) have reached a large audience around the world. Now I am taking a different tack. I write songs with little nuggets of information about mind and brain and mental disorders as a way to hopefully stimulate interest in brain and mind, hoping the listener might then hunger to know more. Maybe they will go to the web, or even pick up a book on the brain. It is an experiment, the outcome of which is still unknown. Perhaps it will work. In the meantime, even if it does not, The Amygdaloids are having a good time.

\section{SUPPLEMENTARY MATERIAL}

The Audio files and Video files for this article canbefound onlineathttp://www.frontiersin. org/human_neuroscience/10.3389/ fnhum.2011.00049/full and http://www. youtube.com/watch?v=AMI3hbgRj6o

\section{REFERENCES}

Fanselow, M. S., and Poulos, A. M. (2005). The neuroscience of mammalian associative learning. Annu. Rev. Psychol. 56, 207-234.

LeDoux, J. E. (1992a). "Emotion as memory: anatomical systems underlying indelible neural traces," in Handbook of Memory and Emotion, ed. S. A. Christianson (Hillsdale, NJ: Erlbaum), 269-288.

LeDoux, J. E. (1992b). "Neural substrates of emotional memory," in Encyclopedia of Learning and Memory ed. L. R. Squire (New York: Macmillan), 483-486.

LeDoux, J. E. (1992c). "Systems and synapses of emotional memory," in Memory: Organization and Locus of Change, eds L. R. Squire, G. Lynch, N. M. Weinberger, and J. L. McGaugh (New York: Oxford), 330-363.

LeDoux, J. E. (1996). The Emotional Brain. New York: Simon and Schuster.

LeDoux, J. E. (2000). Emotion circuits in the brain. Annu. Rev. Neurosci. 23, 155-184.

LeDoux, J. E. (2002). Synaptic Self. New York: Viking.

LeDoux, J. (2007a). The amygdala. Curr. Biol. 17, R868-R874.

LeDoux, J.E. (2007b). Emotional memory. Scholarpedia. Available at: http://www.scholarpedia.org/article/ Emotional_memory

Maren, S. (2005). Synaptic mechanisms of associative memory in the amygdala. Neuron $15,783-786$.

Maren, S., and Quirk, G. J. (2004). Neuronal signaling of fear memory. Nat. Rev. Neurosci. 5, 844-852.

Pape, H. C., and Pare, D. (2010). Plastic synaptic networks of the amygdala for the acquisition, expression, and extinction of conditioned fear. Physiol. Rev. 90, 419-463.

Phelps, E. A., and LeDoux, J. E. (2005). Contributions of the amygdala to emotion processing. From animal models to human behavior. Neuron 48, 175-187. 
Rodrigues, S. M., Schafe, G. E., and LeDoux, J. E. (2004). Molecular mechanisms underlying emotional learning and memory in the lateral amygdala. Neuron 44,75-91.

Sah, P., Westbrook, R. F., and Luthi, A. (2008). Fear conditioning and long-term potentiation in the amygdala: what really is the connection? Ann. N. Y. Acad. Sci. $1129,88-95$.

Squire, L. R. (1986). Mechanisms of memory. Science 232, 1612-1619.
Tully, K., and Bolshakov, V.Y. (2010). Emotional enhancement of memory: how norepinephrine enables synaptic plasticity. Mol. Brain 13, 15-23.

Walker, D. L., Toufexis, D. J., and Davis, M. (2003). Role of the bed nucleus of the striaterminalis vs. the amygala in fear, stress, and anxiety. Eur. J. Pharmacol. 28, 199-216.

Received: 28 April 2011; accepted: 09 May 2011; published online: 01 June 2011.
Citation: LeDoux J (2011) Music and the brain, literally. Front. Hum. Neurosci. 5:49. doi: 10.3389/ fnhum.2011.00049

Copyright (C) 2011 LeDoux. This is an open-access article subject to a non-exclusive license between the authors and Frontiers Media SA, which permits use, distribution and reproduction in other forums, provided the original authors and source are credited and other Frontiers conditions are complied with. 